\title{
6. Fazit
}

Die Analyse durch den Locus ITS ist im Gegensatz zur klassischen morphologischen Artbestimmung eine zeiteffiziente Variante unbekannte Pilzproben durch Datenbankabgleich einzusortieren. Dies setzt jedoch voraus, dass innerhalb der Datenbanken auch genügend Vergleichssequenzen vorhanden sind, die bis zur Artebene richtig deklariert wurden. Um es jedoch ausschließlich zur Ermittlung neuer Arten nutzen zu können, bedarf es einer breiten geografischen Abdeckung mit ausreichender Individuenzahl der unterschiedlichen Populationen, um die möglichen Polymorphismen innerhalb der Nukleotidsequenz besser einschätzen zu können. Jedoch haben die hier gelieferten Ergebnisse durch den ITS-Locus in Subulicystidium longisporum klare genetische Unterschiede ans Licht gebracht, die zum Teil auch durch die unterschiedlichen Sporenformen bestätigt werden konnten. Um die einzelnen Kladen und vor allem die vielen Singletons eindeutig zu positionieren, bedarf es jedoch der Untersuchung weiterer morphologischer Merkmale und/oder zusätzlichem Probenmaterial für die molekulargenetische Untersuchung. Es sollte dabei jedoch nicht vergessen werden, dass auch wenn die genetischen Distanzen hoch sind, es sich dennoch nicht um unterschiedliche Arten handeln muss, denn das klassische Artkonzept setzt voraus, dass sich die unterschiedlichen Arten nicht im Genfluss zueinander befinden (Kunz 2012b). Dies lässt sich allerdings weder durch die Morphologie noch das DNA-Barcoding klar ermitteln, sondern erfordert zwingend Kreuzungsversuche. Der ITS-Locus lieferte innerhalb der hier untersuchten Pilzproben aber einen klaren Ansatzpunkt zur Identifizierung bestehender Unklarheiten und Widersprüche innerhalb der morphologischen Artabgrenzung. 